\title{
Description of the process of information flows formalization in the quality management system of education
}

\author{
T. E. Smolentseva ${ }^{1}$, E. G. Berger ${ }^{1}$ and I. S. Gantz ${ }^{1}$ \\ ${ }^{1}$ MIREA - Russian Technological University, 78, Vernadsky pr., Moscow, 119454, Russia
}

\begin{abstract}
The paper considers the detailed information flows circulating in the training quality management (TQM) system of technical universities in the formulation of control actions (CA). This made it possible to detail information flows (IF), formalize them, as well as their interrelationships, and obtain a scheme with the participation of the developed automated information system for reference decision support (AIS RDS). A detailed analysis of the existing information in the considered system providing hydrocarbon production has been carried out. This made it possible to determine the most complete set of parameters for the initial development of the AIS RDS. Such points as purpose, necessary initial information, consumers of the received information, presentation on external media are defined for each element.
\end{abstract}

\section{Keywords}

Information flow, quality management, education

\section{Introduction}

Management decisions made in the UKOVUZ system are very often based on subjective decisions, but not on the basis of scientific methods. This fact is justified by a number of objective reasons that follow from the peculiarities of universities functioning. An example of factors influencing this process is shown in Figure 1:.

The complexity and multipurpose nature of the university functioning, the alternativeness of its evaluation has the following reasons:

- a decision maker (DM) cannot fully carry out quantitative measurements of pedagogical and social and psychological factors; therefore, his decisions are based largely on inferences that may not be expressed in quantitative values;

- optimal decisions of the i-th level depend on a decision maker made at the (i)-th level of the university structure, and this decision will not be unambiguous;

- a process of CA adoption is influenced by various uncontrolled impacts;

- quantitative factors of the university functioning are sometimes given not in the form of specific values, but in the form of interval values. 


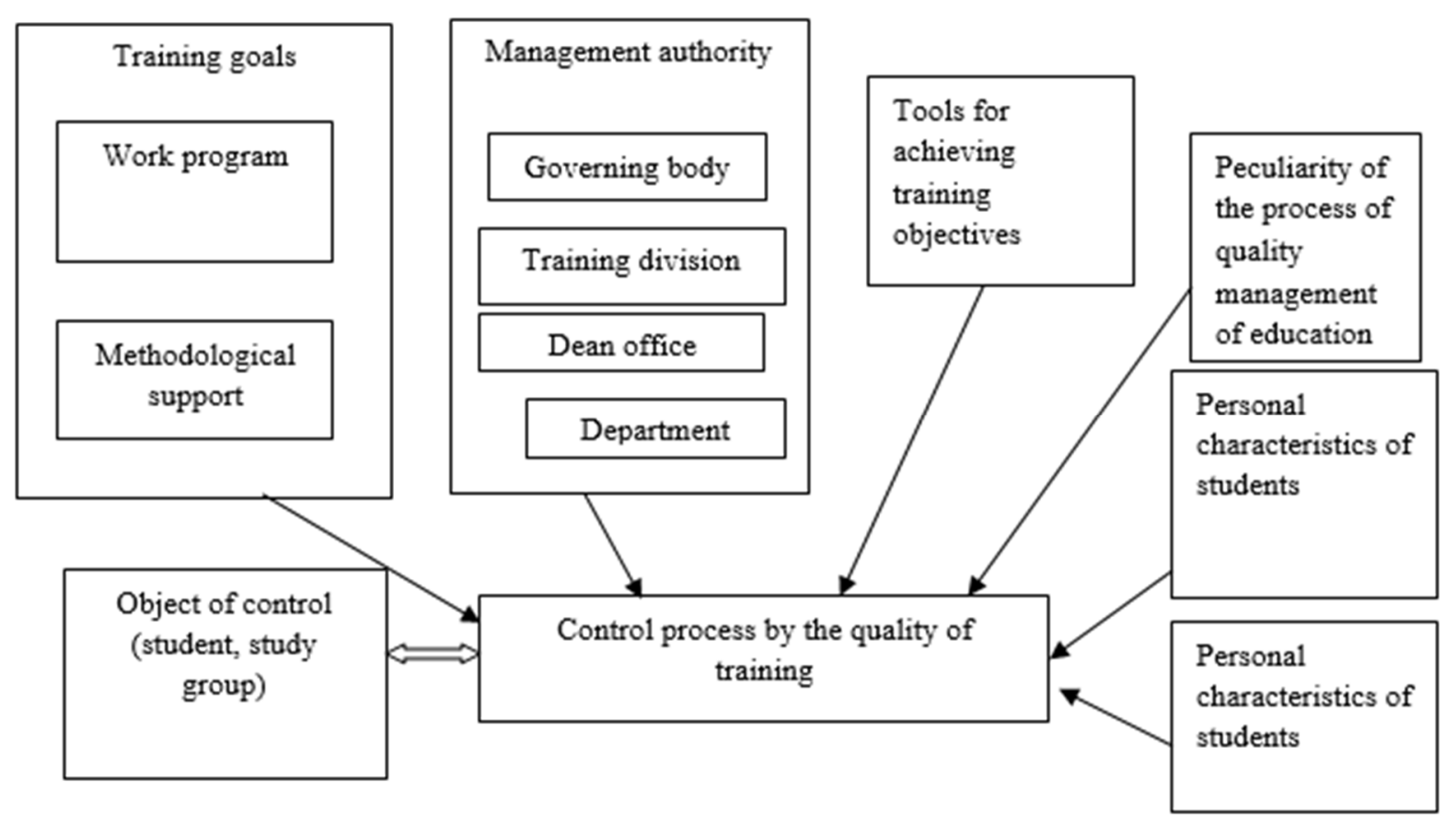

Figure 1: Block diagram of factors influencing the TQM process

\section{Discussion}

The training quality management (TQM) on the basis of system analysis is divided into separate control cycles. Any TQM cycle of the whole TQM structure is identical and it does not depend on the level of the governing body of the university.

Consider in more detail the IF circulating in the TQM during the formation of the CA. The main parameter affecting the optimality of the functioning of the TQM is the CA generated by a decision maker on the basis of the providing information (PI).

A control action development is carried out on the basis of the PI displayed by the IF $I_{0}$. PI is formed on the basis of the basic information (BI) subdivided into:

- information on the results of monitoring current progress and (or) attendance and on the results of midterm (session) monitoring of progress;

- information of the relevant regulatory documents;

- additional information (e.g., the definition of governing bodies or objects of control for the generated hydrocarbon, etc.) $[1,2]$.

\section{Materials and methods}

Consider an element of basic information (BI). It results of knowledge control in more detail. Its value is the main one when obtaining $I_{o}$. Estimations for the current academic achievements and attendance of students in classes for a discrete period of time (a day, week, month, semester), form an IF $I_{b}=\left\{\left(n, f, q, r, P_{n f q r}\right)\right\}[4,8]$

where: $n=\overline{1, N}$ is number of departments;

$f=\overline{1, F}$ is number of faculties;

$q=\overline{1, Q}$ is number of student groups;

$r=\overline{1, R}$ is number of students in a study group;

$P_{n f q r}=2 \div 5$ (current academic achievements);

Estimations of the results of midterm (session) control of academic achievements form PF $I_{b_{01}}=$ $\left\{\left(n, f, q, r, P_{n f q r}\right)\right\}$

where: $n=\overline{1, N}$ is number of departments; 
$f=\overline{1, F}$ is number of faculties;

$q=\overline{1, Q}$ is number of student groups;

$r=\overline{1, R}$ is number of students in the student group;

$P_{n f q r}$ is $2 \div 5$ (code of the mark given on the exam or graded test);

-1 (no credit)

-6 (credit)

IF is formed independently and it has different periods of formation and different informationcarrying media. Grades on current academic achievements and student attendance (with the presentation of reasons for absence) are recorded daily by the teachers of the departments in special journals for recording current academic achievements and attendance. Grades for examination progress are recorded during examination sessions by professors of departments in the test and examination sheets, as well as in directions for retake [6].

The interaction of IF in the TQM system is carried out as follows.

The $\mathrm{IFI}_{b_{01}}$ branches out into departments and information is converted based on a set of operators $H_{k}=\left\{h_{k 1}, \ldots, h_{k N}\right\}$. As a result, the IF goes from the departments to the corresponding faculty $I_{O n}^{k}=h_{k n}\left(I_{b_{01}}\right)$.. IF $I_{O n}^{k}$ and $\boldsymbol{I}_{\boldsymbol{b}_{\boldsymbol{O} 2}}$ branches out to the faculties of the university, where information is processed by sets of operators $H_{f}=\left\{h_{f_{1}}, \ldots, h_{f_{\mathrm{M}}}\right\}$. As a result, IF enters the educational department from the dean's offices $I_{O_{m}}^{f}=h_{f m}\left(I_{b_{O 2}}, I_{O_{n}}^{k}\right)$.

IF $I_{b_{O 2}}, I_{O n}^{k}$ and $I_{O_{m}}^{f}$ in the training division are transformed by a variety of operators $H_{y_{o}}=$ $\left\{h_{y o 1}, \ldots, h_{y o L}\right\}$. As a result, IFs $I_{O l}^{y o}=h_{y o l}\left(I_{b_{O 2}}, I_{O n}^{k}, I_{O m}^{f}\right)$ will be received.

On the basis of the PI, the corresponding CA $U^{a b}$ are developed. They are directed to the subordinate units of the university and to the study groups through the educational staff (ES) and supporting educational staff (SES), where $a$ is source of the corresponding IF and it can take the following values:

- management authority of the university;

- management of the educational division;

- faculty authority;

- management of departments;

- curators;

$\sigma$ is receiver of the corresponding IF and can take on the values:

- management of the educational division;

- faculty authority;

- managements of departments;

- curators;

- $\quad$ educational staff. $[3,5]$

It is necessary to use AIS RDS for BI processing. Then the BI diagram of the TQM process can be structurally presented in the form described in Figure 2:. 


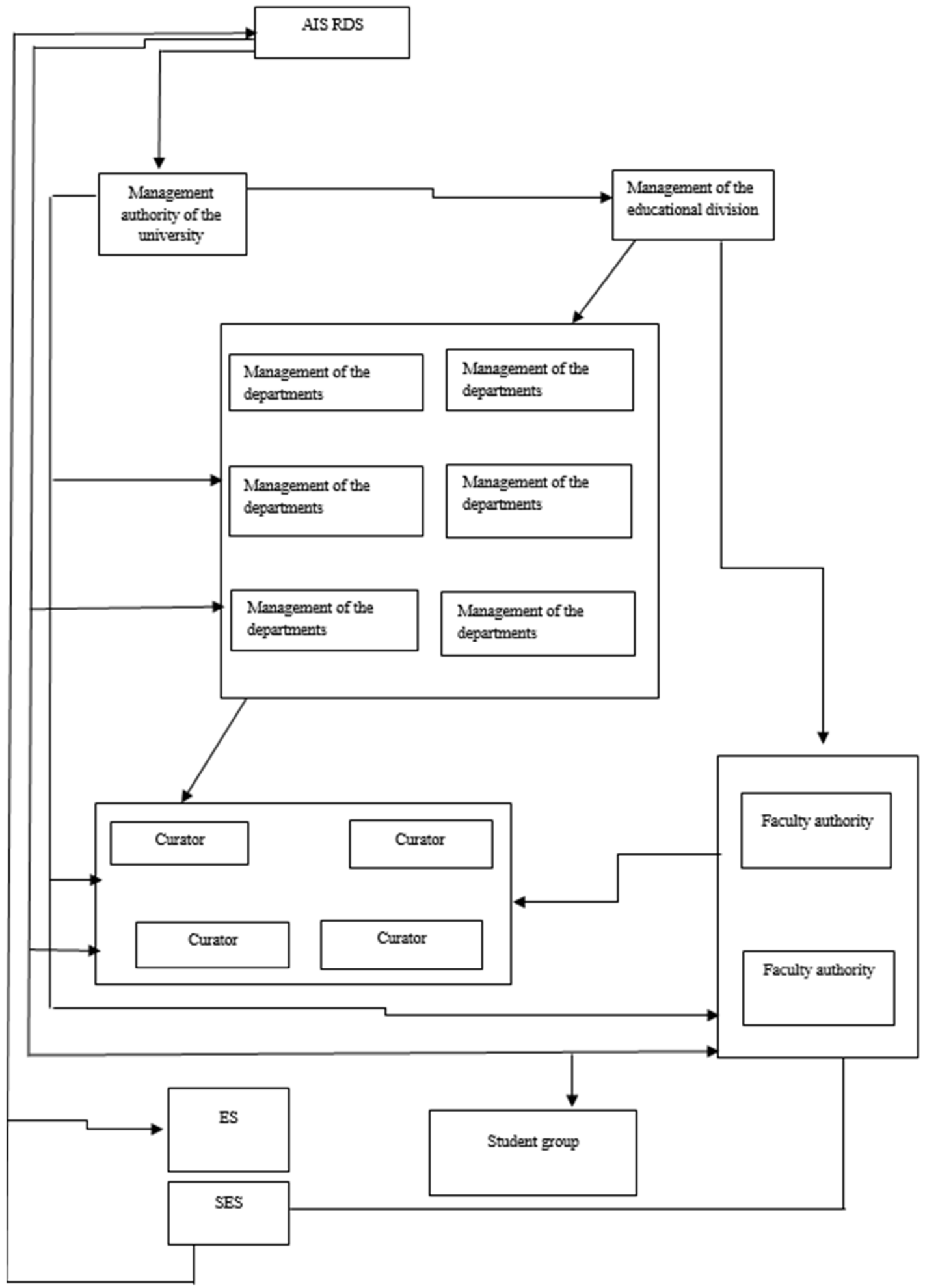

Figure 2: PI of the TQM process using AIS RDS

IF BI combines information on current performance, results of midterm (session) control, achievements of the whole university, attendance of classes and has the form:

$$
I_{b_{O}}=\left\{\left(f, k, a, p, r, g, q, d, v, P_{\text {fkaprgqdv }}\right)\right\}
$$

where: $f=\overline{1, F}$ is index of dean's offices (faculties) of the university;

$k=\overline{1, K}$ is university courses index;

$a=\overline{1, A}$ is index of the departments of the university; 
$p=\overline{1, P}$ is index of subjects taught at the university;

$r=\overline{1, R}$ is university professors' index;

$g=\overline{111, F K N_{f k}}$ is index of the educational groups of the university;

$N_{f k}$ is number of student groups at the faculty "f" of "k" course;

$q=Q_{g}$ is number of students in student group $g_{0}$;

$d=\overline{D_{N}, D_{T}}$ is index by dates of classes;

$D_{N}$ is date of the beginning of the collection of information;

$D_{T}$ is date of the last entered information;

$v=\overline{0, V}$ is index according to the type of classes:

0 - current;

1 - exam

2 - total for the month;

3 - final for 1 semester;

4 - final for 2 semester;

5 - credit.

6 - course work;

$P_{f k a p r g q d v}$ is result of the control of the lesson:

$1-$ credit

6 - no credit;

$7-$ be absent for an unknown reason;

8 - be ill;

9 - cleaning day

10 - vacation;

11 - freshman meeting

Information from examination sheets, gradebooks and class attendance are entered by the database into the AIS RDS.

Information processing procedures AIS RDS are made on the basis of the transformation of the IF through a variety of functions $H=\left\{h_{1}, \ldots, h_{N}\right\}$. As a result of this, the IF PI is formed, where $a$ is a recipient of the PI. Recipients $a$ are:

- university authority;

- management of the educational division;

- faculty authority;

- management of departments;

- curators.

On the basis of the received PI, the corresponding IF $U^{a b}$ are developed, which affect the subordinate bodies and (or) student groups through the ES and SES.

Control objects of control $\sigma$ are:

- management of the educational division;

- faculty authority;

- management of departments;

- curators;

- ES;

- $\quad$ SES.

The possible combinations of $a$ and $b$ are defined in Figure 2:.

\section{Conclusion}

IF in the TQM system can be represented as control cycles. To describe the processing process of BI and PI circulating in the system, it is necessary to use AIS RDS. Such points as purpose, necessary initial information, consumers of the received information, presentation on external media are defined for each element $[7,9]$. 
All objects are selected; their attributes and object relationships are defined. The conceptual model of the AIS RDS database has been developed based on this and taking into account the requirements imposed on the organization of storage and processing of data circulating in the system (Figure 3:).

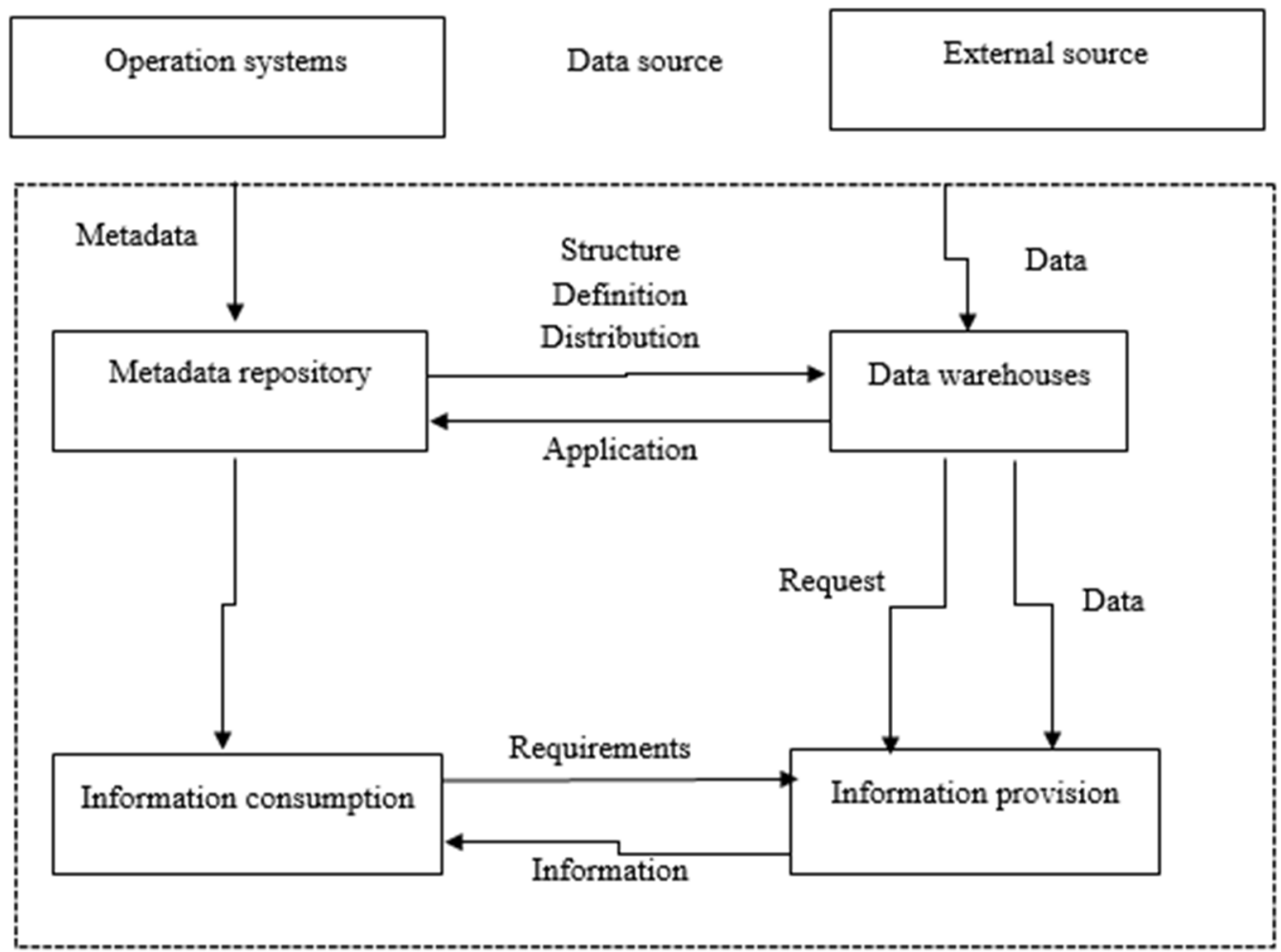

Figure 3: Conceptual model of a data warehouse

\section{References}

[1] N. N. Moiseev, Mathematical problems of system analysis, Moscow, Librokom, 2018.

[2] V. I. Sumin, T. E. Smolentseva, A technique for grouping basic information for information processes in complex systems, Scientific bulletin of Belgorod State University, Economics, Informatics, 13(210) (2015) 104-8.

[3] A. S. Zuev, R. G. Bolbakov, About telecommunication services based on virtual reality technologies, Russian technological journal 5(6) (2017) 3-10. https://doi.org/10.32362/2500316X-2017-5-6-3-10.

[4] O. A. Lastochkina, A. S. Kravchenko, T. E. Smolentseva, Building the structure of hierarchical organizations, Bulletin of the Voronezh Institute of the Ministry of Internal Affairs of Russia 3 (2018) 75-9.

[5] E. G. Berger, The main directions of assessing the efficiency of the enterprise, Collection of articles of the International Scientific and Practical Conference "Edge of science" (2017) 50-8.

[6] A. Yu. Popovich, Dissertation "Synthesis of hierarchical control systems" 05.13.10, Place of protection: Inst systems analysis of RAS (Moscow) (2011) 179.

[7] B. Ya. Sovetov, S. A. Yakovlev, Modeling of systems, Moscow, Higher school, 2015.

[8] V. I. Sumin, A. E. Nikitin, T. E. Smolentseva, Optimization of the composition of the supporting information for the development of control actions, Modern problems of science and education 2 (2015) 194.

[9] V. M. Ilyushechkin, Basics of using and designing databases, Moscow, Yurayt, 2015. 